\title{
Flood Vulnerability and Risk Maps in Taipei City, Taiwan
}

\author{
Yi-Chieh Lin, Ming-Hsi Hsu, Tsang-Jung Chang \& Meng-Yuan Tsai \\ Department of Bioenvironmental Systems Engineering, National Taiwan University, Taipei, Taiwan \\ Wen-Cheng Liu \\ Department of Civil and Disaster Prevention Engineering, National United University, Miaolii, Taiwan
}

\author{
Albert S. Chen, Michael J. Hammond, Slobodan Djordjević \& David Butler \\ Centre for Water Systems, College of Engineering, Mathematics and Physical Sciences, University of Exeter, \\ United Kingdom
}

\begin{abstract}
This paper presents the process of constructing a flood risk map in Taipei City. The study calculates the social vulnerability index (SVI) for flooding at a district level, based on five factors including (1) female population (2) alone living elderly (3) low-income households (4) household income and (5) household possessions. The index is determined according to the factor ratios in a district comparing to the statistical average across Taipei City. By combining the SVI with spatial varied flood potential information simulated by a hydraulic model, the flood risk index is obtained for district level that has an area of about $0.2 \mathrm{~km} 2$. Results show that the flood risk in Taipei City changed from 2002 to 2010 due to changes in the demographic structure. During the period from 2002 to 2004, the most obvious change of flood risk occurred in the Wanhua district due to the increase in the ratio of household possessions, which escalated the vulnerability to flooding. Between 2005 and 2007, the ratio of household possessions dropped in the Nankang district such that the flood risk reduced mostly in the region.
\end{abstract}

\section{INTRODUCTION}

To estimate the impact of a hazard, a conversion is often required to translate the hazard information into risk, which vulnerability is often used as an index for the conversion. Vulnerability is the ability of a system, groups or individuals can bear when suffer from harm. Social scientists and climate scientists often mean different things when they use the term "vulnerability" (Adger et al., 2004). Chung (2006) reviewed various literatures and summed up the definition as

"Vulnerability actually is a forward-looking concept, which is focus on the possible future impact, combined with the impact of environmental and to make predictions, it is a thinking point of precautionary. The goal of vulnerability through the action to reduce hazard damage, and the mitigation is a social activity, we must apply to management and practical action plan to assess hazardous event."

Cardona (2003) found the relationship between hazard and vulnerability is a kind of convolution and concomitance, vulnerability cannot be established without hazard, and the threat of hazard neither exists if there is no vulnerability; both of these are the best composition to assess the risk of disaster impact. Adger et. al, (2004) defined the risk as a function of hazard and social vulnerability: R (Risk) $=\mathrm{H}$ (Hazard) $\times$ V (Vulnerability), which represents the interaction of natural or man-made hazard, the community or factors of social vulnerability, and the expected of loss or damage. The consequence of the hazard depends on the probability of occurrence of a hazard and on the social vulnerability of the exposed system.

Some hazard analysis estimated and associated the risk with the probability of exceedance flooding (Merz and Thieken 2004). The commonly used method is that the flood frequency analysis (e.g. Stedinger et al. 1993) or by changing the correlation between return period and the discharges to define the new flood scenario for assessment.

The vulnerability of a system, subsystem, or system component is the likelihood to experience harm due to exposure to hazards. For example, a society with growing elderly population; the social vulnerability tends to increase. Once a hazard occurs, it will result in great impact on the society. Same hazard event may have different effect to different vulnerability factors (Turner et al., 2003).

In Taiwan, the National Science and Technology Center for Disaster Reduction (NCDR) has established the national flood potential database of Taiwan (Chen et al. 2006), which was aimed to help the government to develop flood disaster mitigation strategies. Nevertheless, the flood potential only provides possible hazard under certain scenarios. The area with greater flood potential is not necessary to have higher risk. A further investigation is required to convert hazard information into risk, by taking social economic activities into account, such that the decision makers can easily determine and prioritize the strategies to prevent hazards and mitigate the impacts. 
Studies have shown that the extreme rainfall events are likely to increase in the future due to climate change. Human technology cannot eliminate natural hazards. However, the hazard risk can be effectively reduced by enhancing the hazard mitigation measures for the vulnerable elements in a system. In this study, a social vulnerability index (SVI) that consists of five factors is applied to evaluate the impact of flooding in the Central Taipei Area (CTA). The spatial distributions of the vulnerability factors and the flood hazards were integrated to determine the SVI at village level.

\section{METHODOLOGY}

The study aims to assess and simulate the interaction between the impacts of flood and social factors, and to produce risk maps to understand the high-risk area. Flood damage is not only related to hazard, but also the vulnerability within the impact area. Therefore, five social vulnerability factors, including (1) female population, (2) alone living elderly, (3) low-income households, (4) household income, and (5) household possessions, are applied to estimate the impact of flooding. The social vulnerability factors have different units, to integrate all factors as a single index, the vulnerability factors are calculated and standardized as the z-score (average standard score) in Eq. (1).

$$
z-\text { score }=\frac{(x-M)}{S D}
$$

where, $\mathrm{x}$ is the factor data, $\mathrm{M}$ is the mean, $\mathrm{SD}$ for standard deviation. The $\mathrm{z}$-scores are therefore integrated to produce the social vulnerability index using Eq. (2).

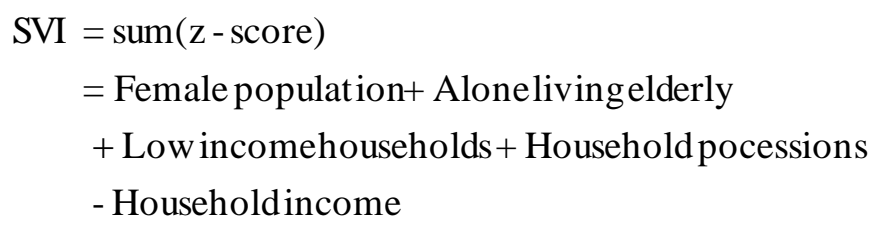

Most of the factors have positive relationship to vulnerability, i.e. the higher z-score is, more vulnerable the social factor is.

A community with higher ratios of female population and elderly people living alone is considered more vulnerable because their physical conditions restrict their response to flooding. The higher number of lower income households indicate that more families would be less capable to withstand the impacts of flooding.

Due to advances in technology and the economic development, luxury household possessions such as electronic products are now very common in many households. Nevertheless, most of the equipment is non-waterproof and very expensive to replace once they are damaged, hence, the amount of household possessions is regarded as a vulnerability factor.

The only exception is the household income, as a family with higher income is considered less vulnerable because it is likely to be more able to avoid the impact and to recover from flooding.

A 2D overland flow model that neglects the inertial terms in momentum equations, based on the assumption that the acceleration terms are small compared with the gravitation and friction terms, was applied to analyze the flood potential in the study. The depth-averaged shallow water equations on the overland surface are written as:

$$
\begin{aligned}
& \frac{\partial d}{\partial t}+\frac{\partial[(1-\beta) u d]}{\partial x}+\frac{\partial[(1-\beta) v d]}{\partial y}=q \\
& -\frac{\partial h}{\partial x}=S_{f x}+\frac{q u}{d g} \\
& -\frac{\partial h}{\partial x}=S_{f y}+\frac{q v}{d g}
\end{aligned}
$$

where, $\mathrm{d}$ is water depth; $\mathrm{h}$ is water stage; $\mathrm{u}$ and $\mathrm{v}$ are velocity components in $\mathrm{x}$-and $\mathrm{y}$-direction, respectively; $\mathrm{t}$ is time; $\mathrm{g}$ is gravitational acceleration; $\mathrm{q}$ is source or sink term; $S_{f x}=n^{2} u \sqrt{u^{2}+v^{2}} / d^{4 / 3}$ and $S_{f y}=n^{2} v \sqrt{u^{2}+v^{2}} / d^{4 / 3}$ are friction slopes in $\mathrm{x}$ - and $\mathrm{y}$ - direction, respectively; $\mathrm{n}$ is Manning's roughness; and 
$\beta=\sqrt{A_{b} / A}$ is detaining ratio which represents a linear ratio of building area to the total area of interest.

To simulate the flow interactions between the sewer system and the ground surface in urban area, the 2D model is coupled with the SWMM sewer model for modeling. The drainage through inlets to the sewer systems and the overflow from the surcharged manholes to ground surface are used for model linkages between the overland and the sewer flow models. The former is treated as the sink and the latter as the source in the 2D model. Eqs. (3) to (5) are solved by a finite difference numerical scheme, namely the Alternating Direction Explicit (ADE) method, which allows an initial condition with zero water depth and velocity (Hsu et al., 2000).

By combining the SVI with flood potential information, a matrix as shown in Table 1 is formed to generate the flood risk index. In general, the risk matrix can be classified as (1) qualitative analysis (2) quantitative risk analysis (3) semi-quantitative analysis. A semi-quantitative analysis refers to an analysis where the values are not equivalent to the actual extent or frequency of hazards. This study uses the semi-quantitative analysis as risk analysis basis to generate the risk index map of the study area.

Table 1. This risk matrix as a combination of the flood depth and the SVI

\begin{tabular}{|c|c|c|c|c|c|}
\hline \multirow{2}{*}{ Depth } & \multicolumn{5}{|c|}{ SVI } \\
\cline { 2 - 6 } & $-4 \sim-2$ & $-2 \sim 0$ & $0 \sim 2$ & $2 \sim 4$ & $4 \sim 7$ \\
\hline $0 \sim 0.2$ & 1 & 2 & 3 & 4 & 5 \\
\hline $0.2 \sim 0.5$ & 2 & 3 & 4 & 5 & 6 \\
\hline $0.5 \sim 1$ & 3 & 4 & 5 & 6 & 7 \\
\hline $1 \sim 1.5$ & 4 & 5 & 6 & 7 & 8 \\
\hline $1.5+$ & 5 & 6 & 7 & 8 & 9 \\
\hline
\end{tabular}

\section{MODEL APPLICATION AND DISCUSSION}

According to the statistical information, Taiwan will become an aging society, and is one of the counties with the quickest growing aging population ratio. Some report predicted that the aging population rate will reach $12 \%$ in 2014, and exceed $20 \%$ in 2025 . The demographic structure of Taipei City has been changing rapidly, to investigate the risk of an extreme flood event to the current society condition, a historical typhoon event was therefore applied in the study.

In 2001, Typhoon Nari swept Taiwan and brought heavy rainfall with intensity up to $700 \sim 1000 \mathrm{~mm} / \mathrm{day}$ and caused 30 causalities in Taipei City. A levee breach occurred along the Keelung River in the east of the Central Taipei Area (CTA), which resulted in severe flooding in the north and the east part of the CTA. In particular, the flood inundated the Taipei MRT (Mass Rapid Transit) with the maximum flood depth as deep as 5.4 meters at a station. It took around three months for the MRT to full recovery. A filed survey was conducted to investigate the flood extent after the event. However, the investigated record did not include the spatial varied depth information such that the hydraulic model was applied to reproduce the information needed. Figure 1 shows the average flood depth in village level obtained from hydraulic modeling results.

The five vulnerability factors of Taipei City at the district scale were collected from the Department of Budget, Accounting and Statistics of Taipei City Government. The data showed that the female population of Taipei city increased between 2002 and 2010, although the total of elderly people living along did not increase during the same period. However, at the district level, Wanhua District has more elderly people living along than other districts. The proportion of low income households in the whole city increased by $0.64 \%$ from 2002 to 2010. Eqs (1) and (2) were used to calculate the SVI as shown in Figure 2.

The average flood depths were combined with the SVI of district scale to calculate the flood risk index at the village level, as shown in Figure 3. In general, the village with greater flood depths have higher risk index. But for villages in Wanhua district, the risk indices are higher than villages in other districts because it has higher SVI due to the vulnerability factors. Hence, priority of flood mitigation plans in these vulnerable is recommended to reduce the hazard impact effectively. 


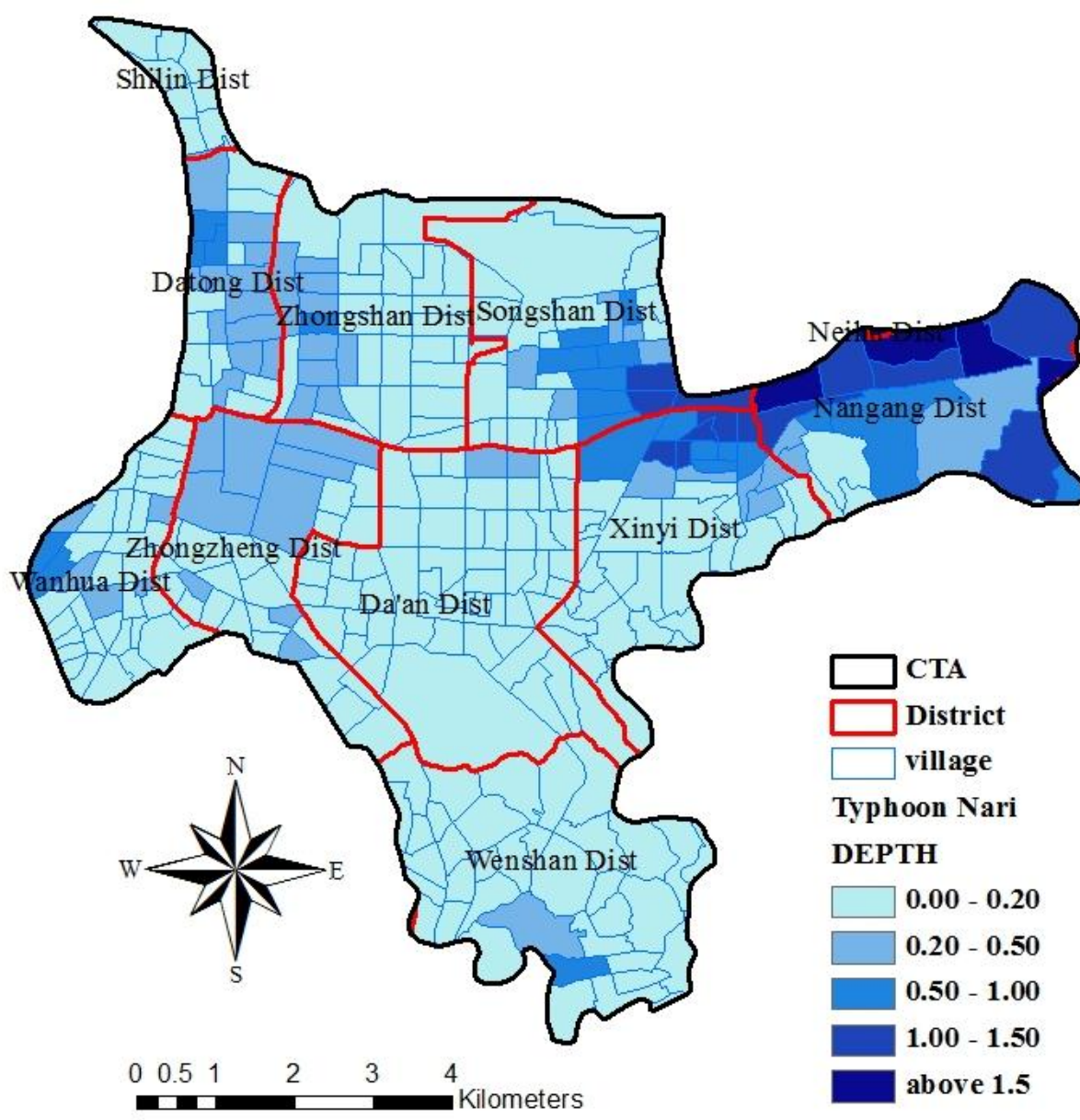

Figure 1. Average flood depth in village scale for the Typhoon Nari event in the CTA from hydraulic modeling results

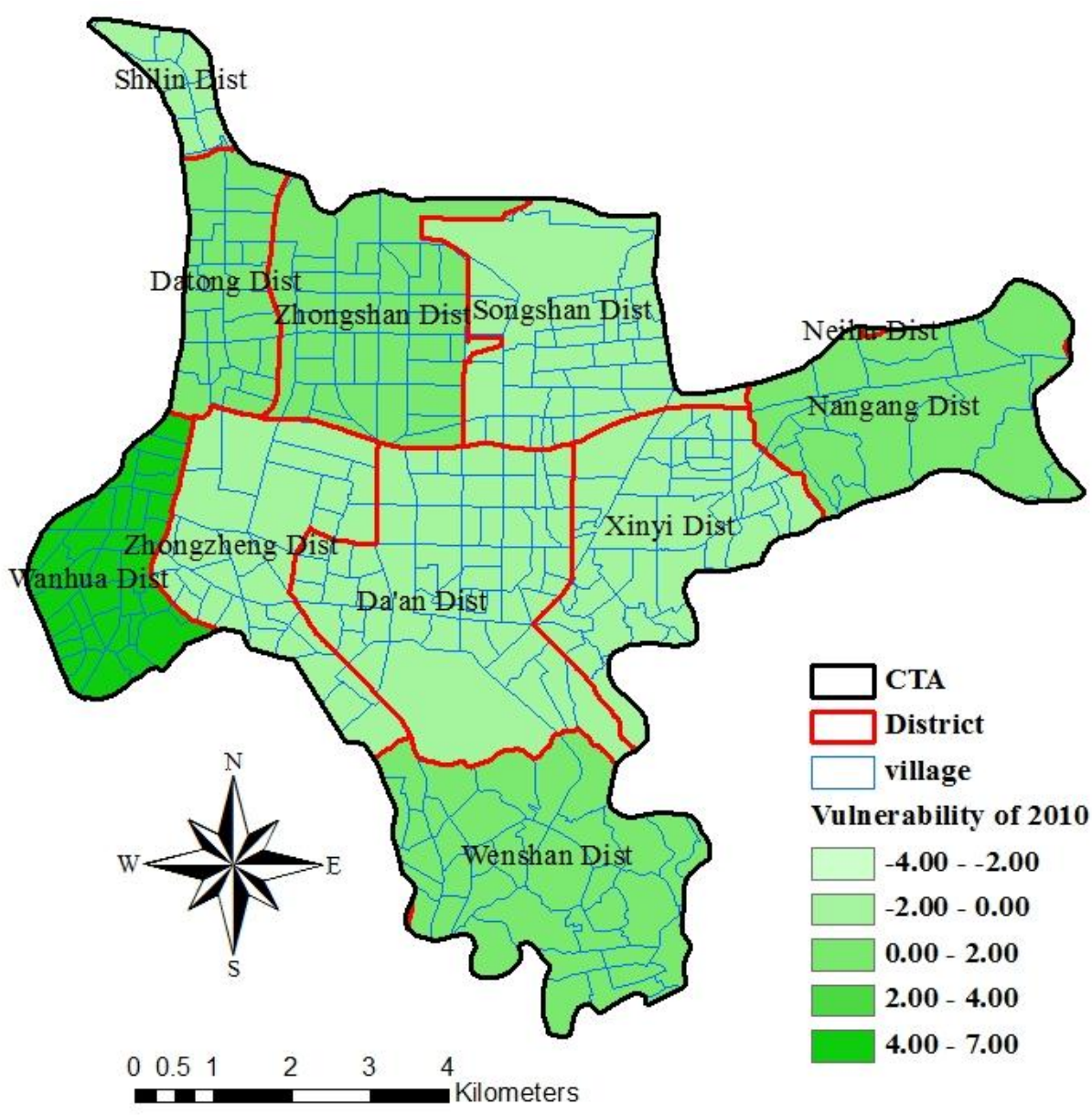

Figure 2. Social vulnerability index of 2010 in the CTA 


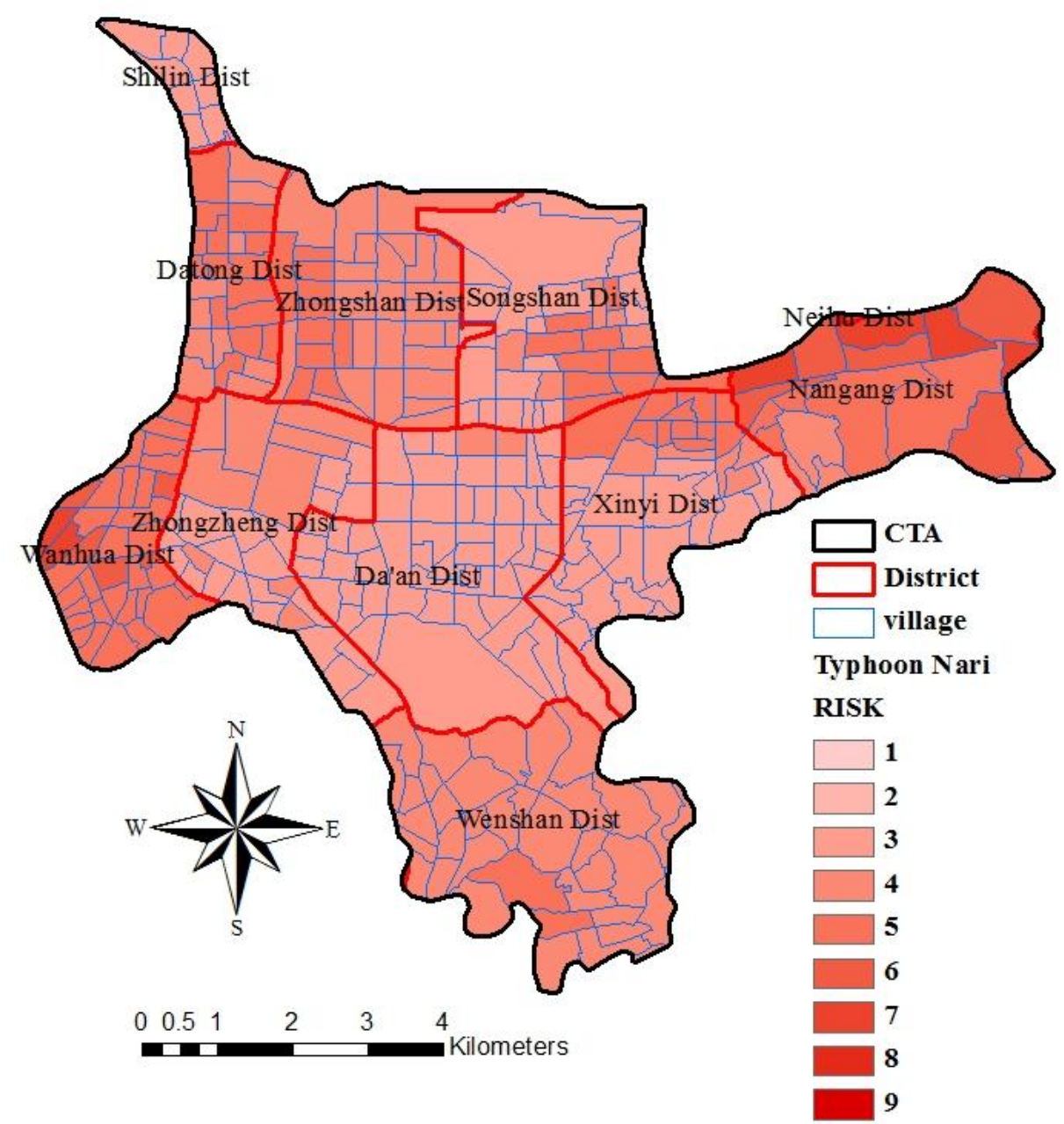

Figure 3. Flood risk index of the CTA in 2010 for an event with similar scale to Typhoon Nari

The previous example shows the possible flood risk under 2010 society condition if an event with similar scale to Typhoon Nari strikes Taipei again. A further examine is applied to analyze the temporal evolution of SVI and risk in the CTA.

Figure 4 shows the SVI of the CTA from 2002 to 2010. The population of alone living elderly and female in Taipei gradually increased and the SVI in Wanhua District reached a peak value 6.4 in 2004. Meanwhile, the district also has the most households with low-income.

On the other hand, the SVI of Wenshan, Da'an, Songshan, Datong and Xinyi Districts did not change obviously since 2007 although some factors in these districts did has a certain percentage change in the years. Figure 4-(d) and 4-(e) show that the SVI value declined in Songshan District, because the ratio of house equipment dropped.

Further, a 100-year return period event was simulated, shown in Figure 5, to assess the flood impact under the social conditions from 2002 to 2010.

Figure 6 shows the risk index for a 100-year event of the CTA under the social conditions from 2002 to 2010. The maximum flood depths are located within the villages in Zhongshan District, according to Figure 5, but the highest risk index is found in a village within Wanhua District that, which has a value 8 in 2010 . It is due to the high SVI of Wanhua District and a large flood depth in that particular village.

The SVI maps can only indicate the vulnerability at district level. By combing with the hazard map, it can clearly point out the exact villages that have higher risk. Hence, the authorities can develop flood mitigation strategies, aiming on those vulnerable communities, to reduce the impact of flooding. 


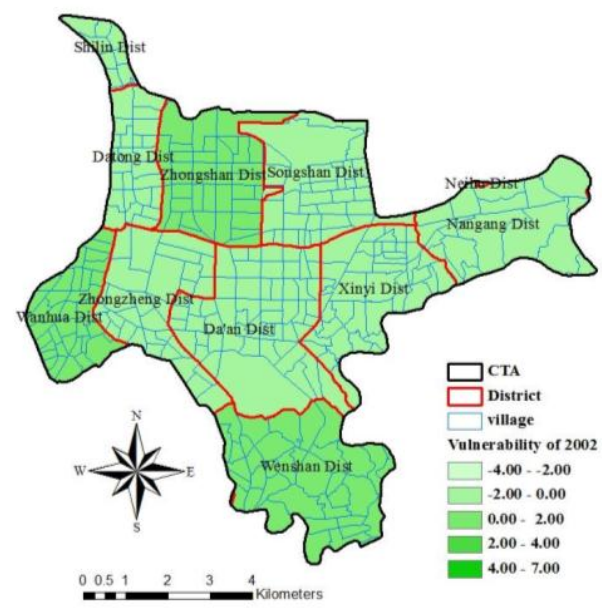

(a)

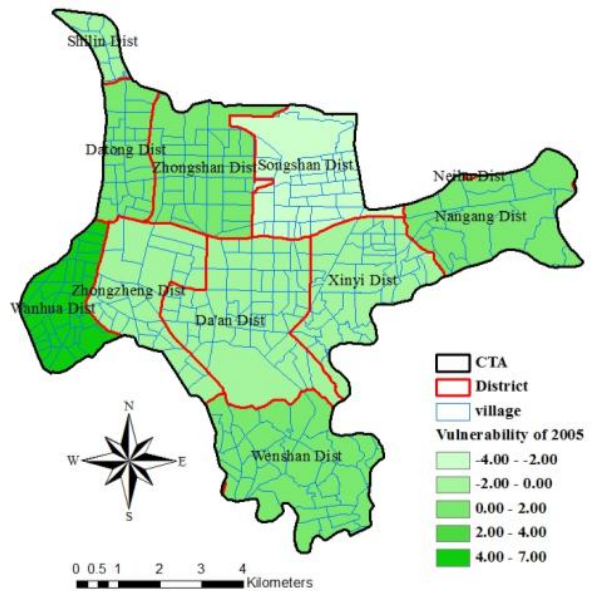

(d)

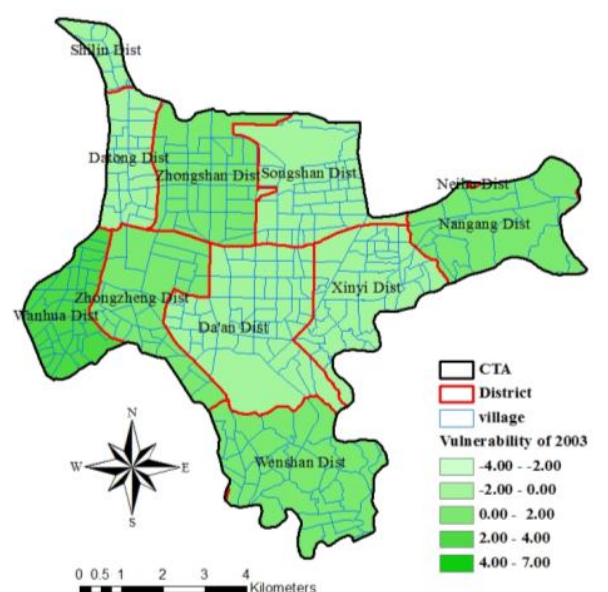

(b)

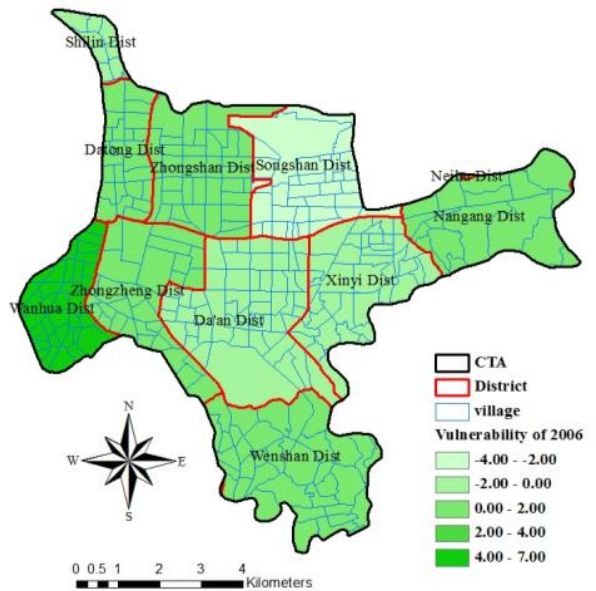

(e)

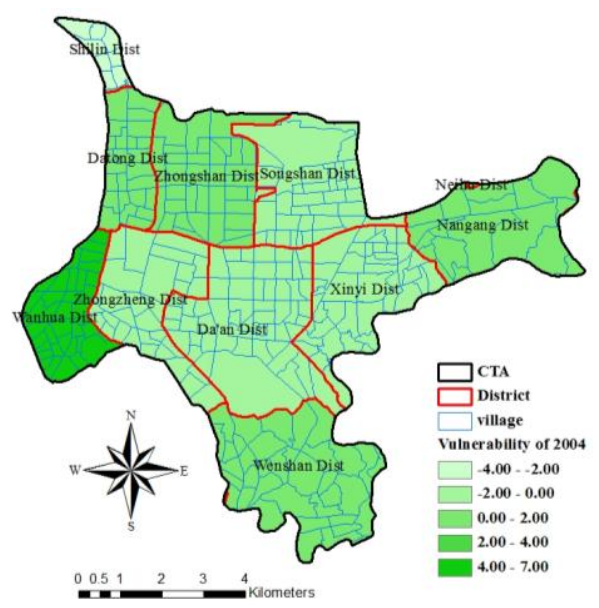

(c)

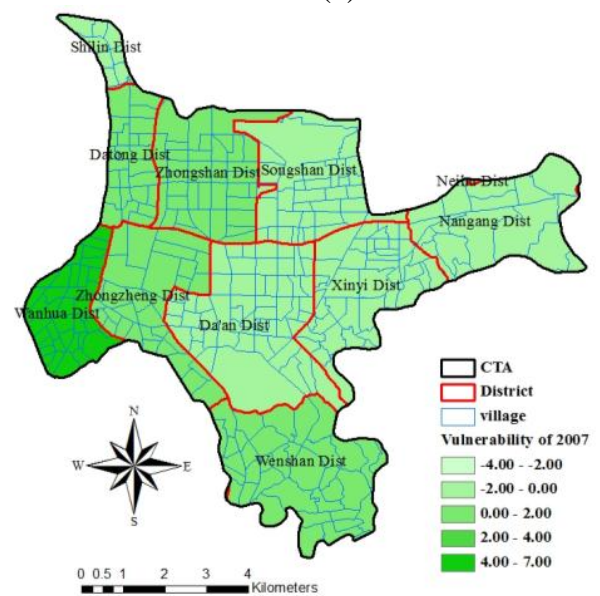

(f)

Figure 4. The SVI map of the CTA from 2002 to 2010.

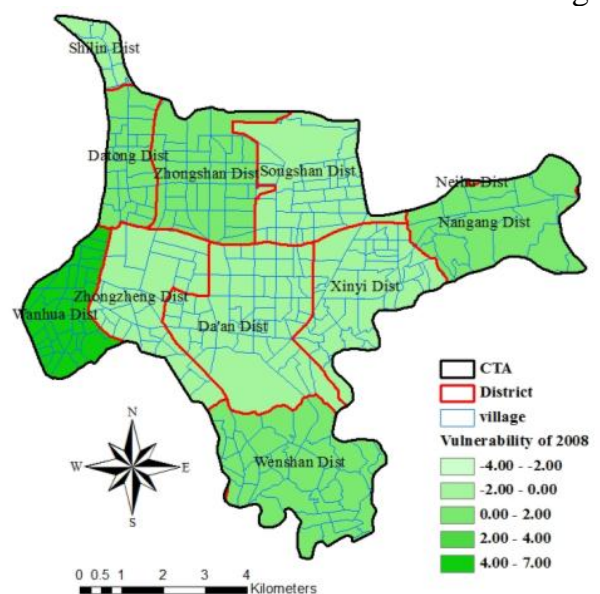

(g)

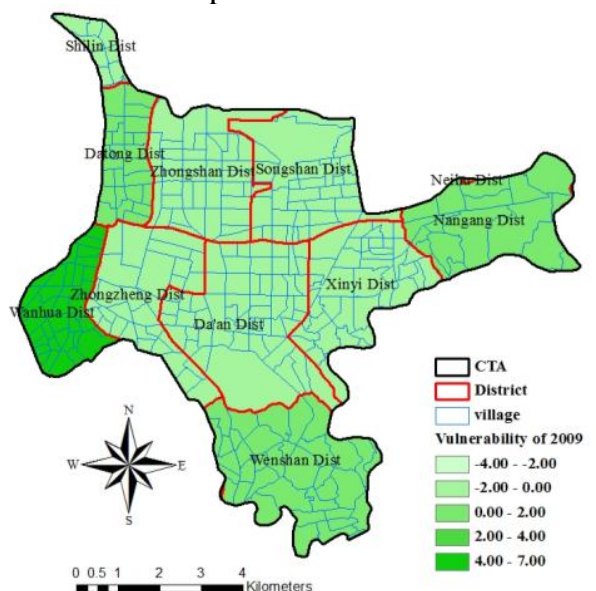

(h)

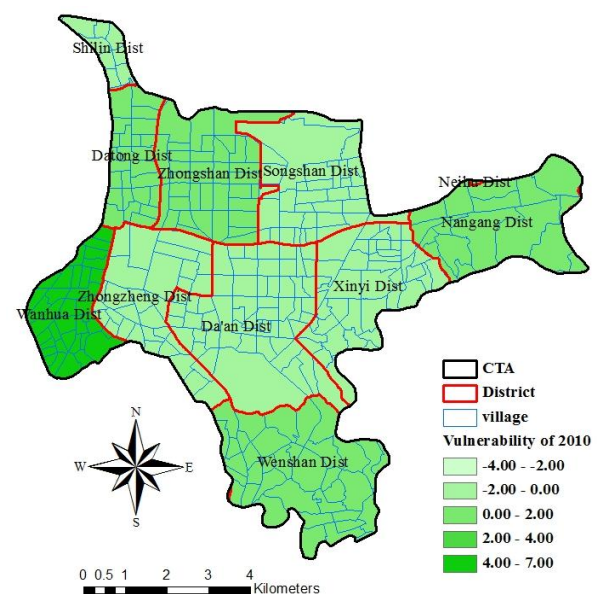

(i)

Figure 4 (cont.). The SVI map for the CTA from 2002 to 2010. 


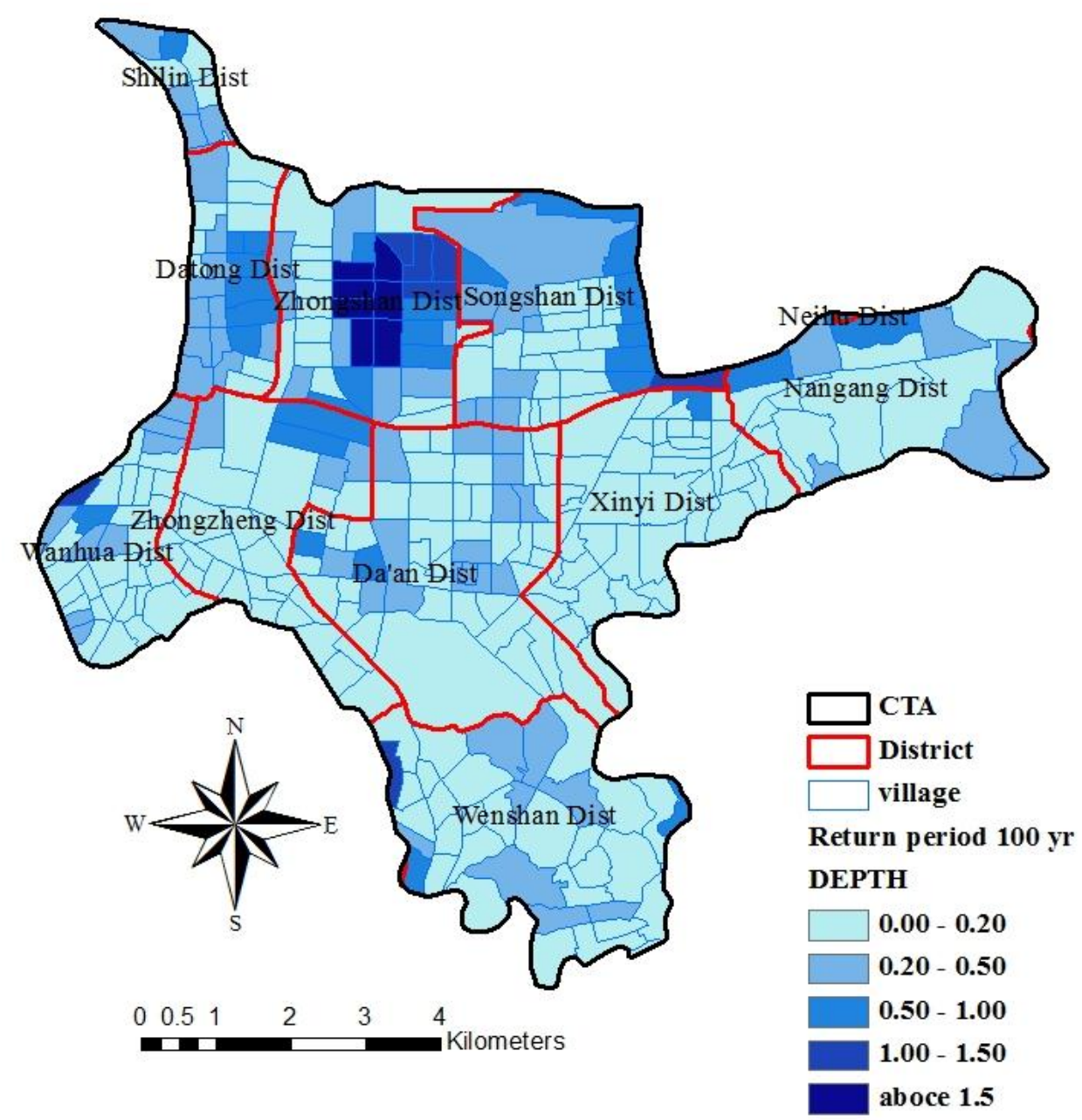

Figure 5. The flood potential map for a 100-year return period event.

\section{CONCLUSIONS}

Five social vulnerability factors have been taken into account, together with flood hazard information, for evaluating the flood risk in the CTA. By considering the temporal variation of demographical data, the study further demonstrated that change of social vulnerability factors and the risk. The analyzing results can help the city government to realize the most vulnerable area within the CTA. Hence, required resource can be allocated to reduce the community's vulnerability to flooding.

In Taiwan, the governments warning mainly rely on the flood potential information to issue early warning during flooding. The study has shown that an area with low flood depth may still face high risk because it has higher social vulnerability factors. Without considering the social factors, such areas may not be highlighted and receive required help in advance or in time.

In the future, the AHP (Analytic Hierarchy Process) will be used to calculate the weights of different factors for reflecting the influence level of different factors in different areas. Furthermore, more social factors, such as hospitals, nursing homes, disabilities, etc., and finer spatial resolution will be used for calculation to improve the accuracy of the approach. 


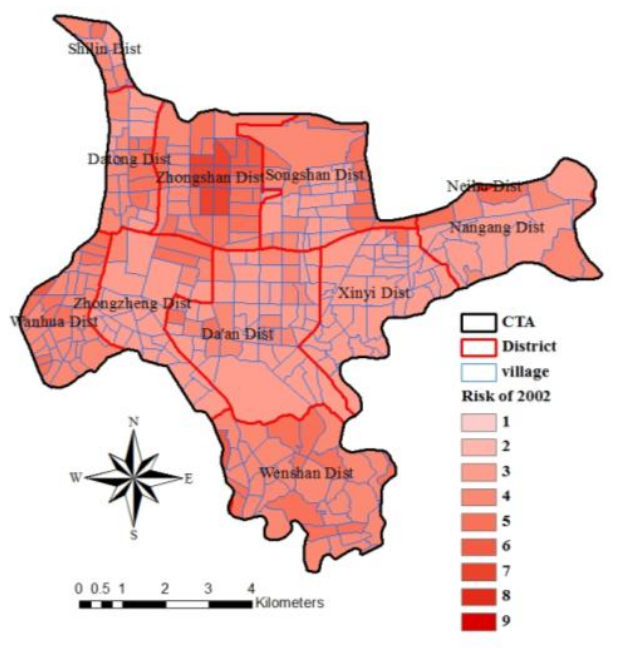

(a)

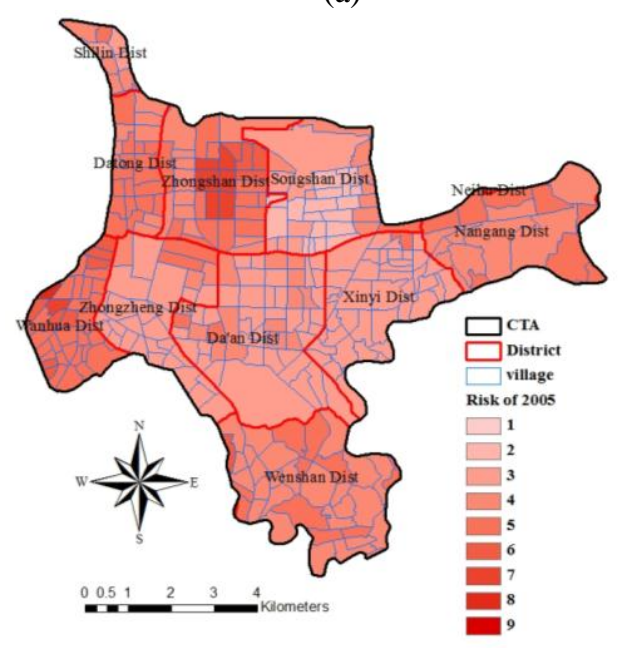

(d)

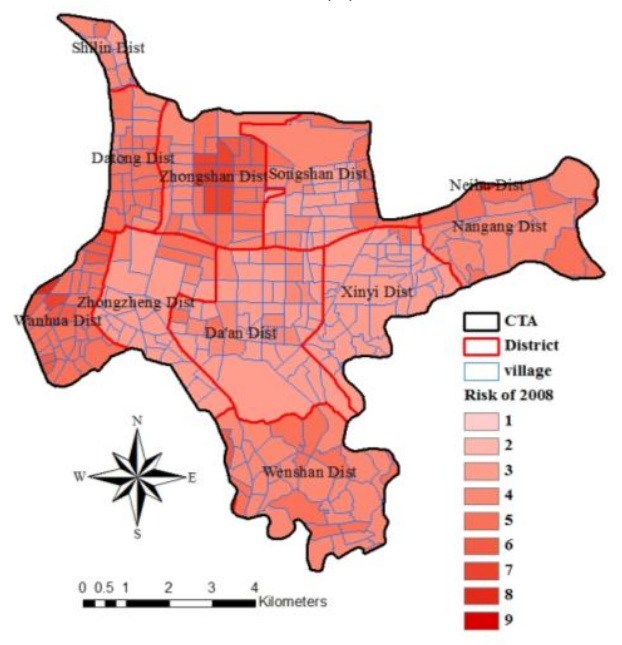

(g)

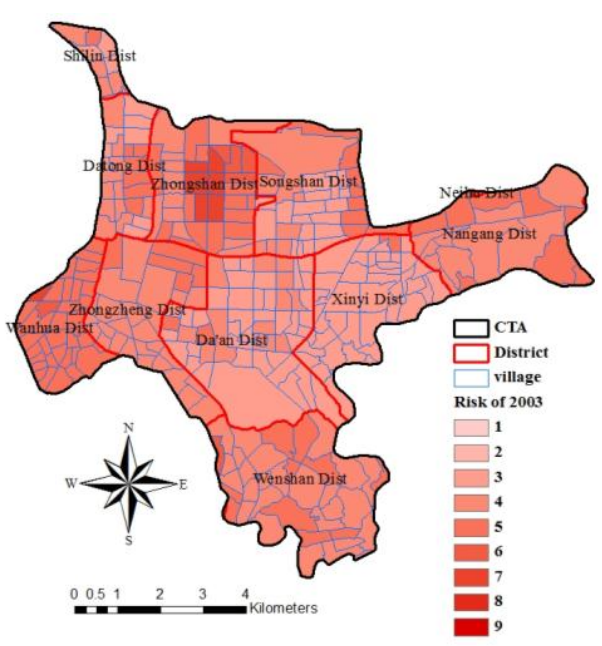

(b)

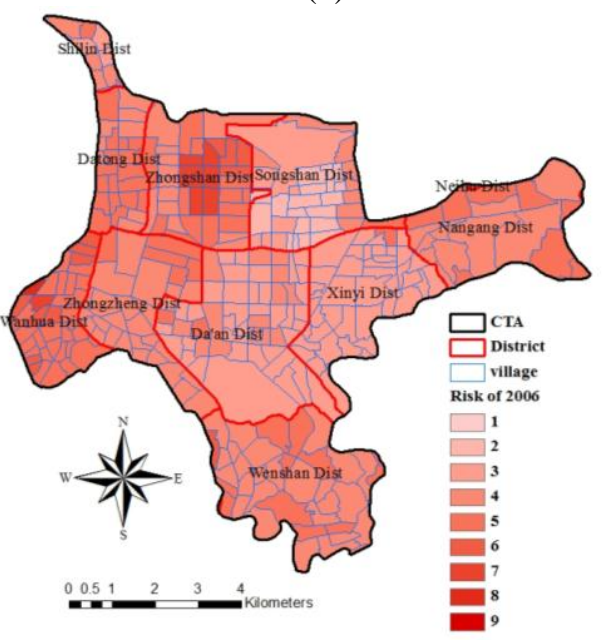

(e)

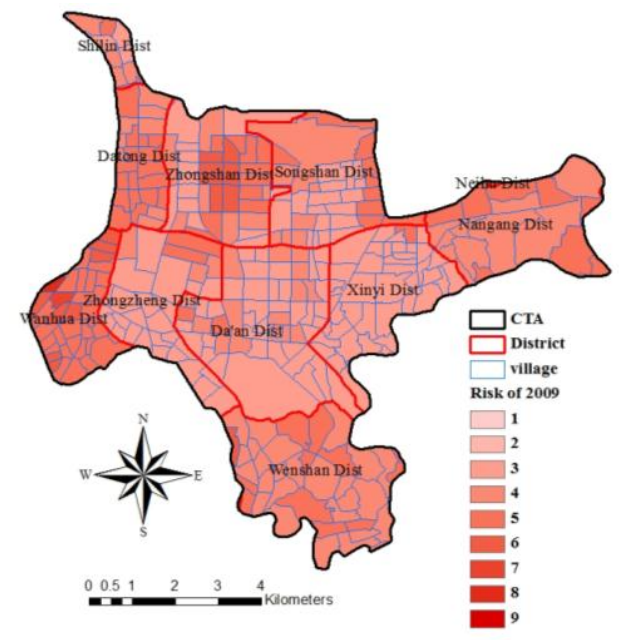

(h)

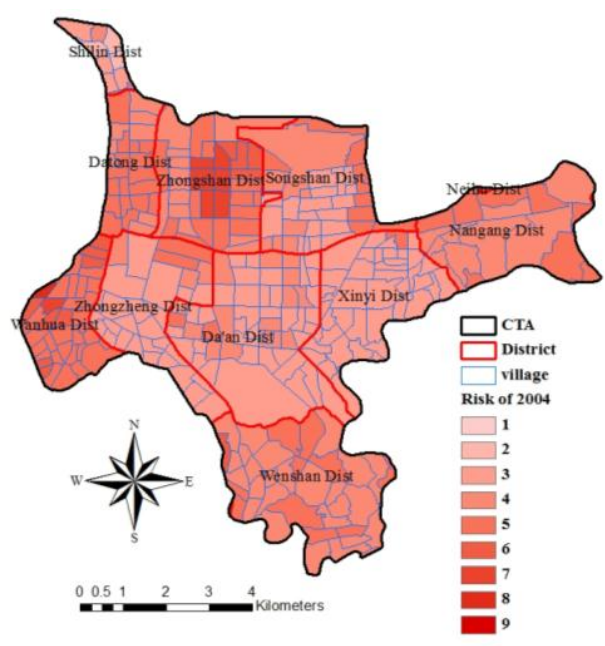

(c)

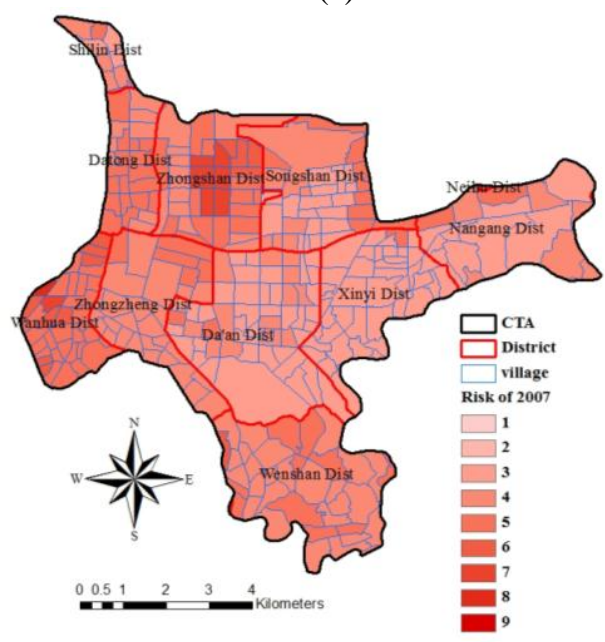

(f)

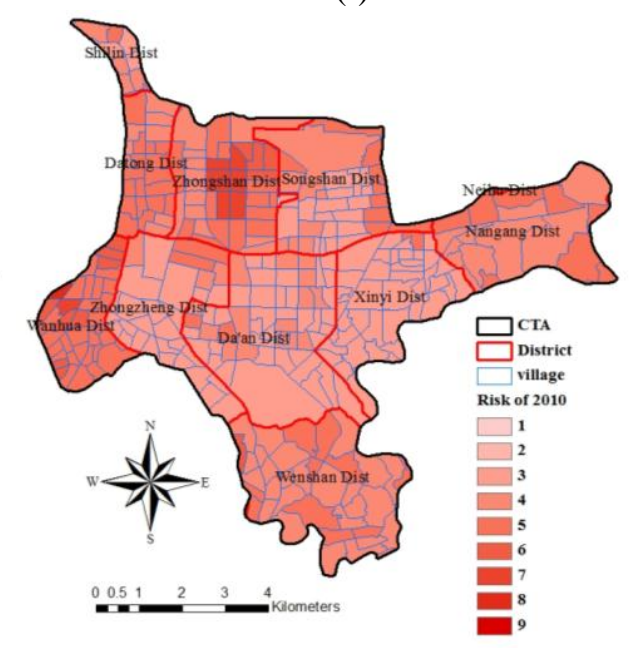

(i)

Figure 6. The risk map for 100year return period of 2002 to 2010. 


\section{ACKNOWLEDGEMENTS}

The work is supported by the National Science Council, Taiwan (NSC 99-2915-I-002-120) and the CORFU project, funded by the European Commission through Framework Programme 7, Grant Number 244047.

\section{REFERENCES}

Adger, W. N., Brooks, N., Kelly, M., Bentham, G., Agnew, M., and Eriksen, S., 2004. New indicators of vulnerability and adaptive capacity. Norwich, United Kingdom: Tyndall ${ }^{\circ}$ Center for Climate Change Research. Technical Report 7.

Apel, H., Aronica, G.T., Kreibich, H. and Thieken, A. H., 2009. Flood risk analyses-how detailed do we need to be? Natural Hazards 49: 79-98.

Brooks, N., 2003. Vulnerability, risk and adaptation: A conceptual framework. Norwich, United Kingdom: Tyndall ${ }^{\circ}$ Center for Climate Change Research. Working Paper 38.

Cardona, O. D., Bankoff, G., Frerks, G., Hilhorst, D., 2003. Mapping Vulnerability: Disasters, Development and People, Chapter 3: The need for rethinking the concepts of vulnerability and risk from a holistic perspective: a necessary review and criticism for effective risk management. London: Earthscan.

Cutter, S. L., 1996. Vulnerability to environmental hazards. Progress in Human Geography 20(4): 529-530.

Cutter, S. L., 2005. Hazards Measurement. Encyclopedia of social Measurement 2: 197 - 202.

Chen, A. S., Hsu, M. H., Teng, W, .H., Huang, C. J., Yeh, S. H., and Lien, W.Y., 2006. Establishing the Database of Inundation Potential in Taiwan. Natural Hazards. 37(1-2):: 107-132.

Chung, C. L., 2006. The Assessment of Vulnerability to Typhoon Disasters in Taiwan Area. Taichung, Taiwan: Chaoyang University of Technology.

Chen, C. S., Hsu M. H., Lin, G. F., Lai, J. S. and Pan, T.Y., 2010. Investigation on Analysis Method of Flood Vulnerability and Risk. Taipei, Taiwan: National Science and Technology Center for Disaster Reduction (NCDR).

Fekete, A., 2009. Validation of a social vulnerability index in context to river-floods in Germany. Natural Hazards and Earth System Sciences 9: 393-403.

FEMA. 2009. Risk mapping, Assessment, and Planning (Risk Map) Multi-Year Plan: Fiscal Years 2010-2014. Federal Emergency Management Agency, U.S.A: Fiscal Year 2009 Report to Congress. Homeland Security.

Hsu, M. H., Chen, S. H., and Chang, T. J. 2000. Inundation Simulation for Urban Drainage Basin with Storm Sewer System. Journal of Hydrology. 234 (1-2): 21-37.

Huang, Y. S., 2007. The Establishment of Vulnerability Evaluation Indexes: The Case study on Shuili Township, Nantou. Taipei, Taiwan: Ming Chuan University.

Merz B., Thieken, A. H., 2004. Flood risk analysis: concepts and challenges. Österreichische Wasser- und Abfallwirtschaft . 56(3-4):27-34.

de Moel, H., van Alphen, J., and Aerts, J., 2009. Flood maps in Europe -methods, availability and use. Natural Hazards and Earth System Sciences 9: 289-301.

Roberts, N. J., Nadim, F., and Kalsnes, B., 2009. Quantification of vulnerability to natural hazards. Georisk 3(3): 164-173.

Shaw, D., Huang, H. H., Ho, M. C., and Lin, S., 2005. Modeling Flood Loss and Risk Perception.-- The Case of Typhoon Nari in Taipei. Fifth Annual IIASA-DPRI Forum Integrated Disaster Risk Management: Innovations in Science and Policy.

Shaw, D., Li, S. J., and Yang, H.S. 2008. Disaster losses and vulnerability assessment. Taipei, Taiwan: National Science and Technology Center for Disaster Reduction (NCDR).

Stedinger, J. R., Vogel, R. M., Foufoula-Georgiou, E., 1993. Frequency analysis of extreme events. Maidment, D. R., New York: Handbook of Hydrology, McGraw-Hill.

Turner II, B. L., Kasperson, R. E., Matson, P. A., McCarthy, J. J., Corell, R. W., Christensen, L., Eckley, N., Kasperson, J. X., Luers, A., Martello, M. L., Polsky, C., Pulsipher, A., and Schiller, A., 2003. A framework for vulnerability analysis in sustainability science. PNAS (Proceedings of the National Academy of Science of the United States of America) 100(14): 8074-8079.

Vogel, C., Moser, S. C., Kasperson, R. E., Dabelko, G. D., 2007. Linking vulnerability, adaption, and resilience science to practice: Pathways, players, and partnerships. Global Environmental Change 17: 349-364.

Wu, D. L., Fan, R. S., 2009. The report of statistical applications analysis: The vicissitudes of Taipei City population. Taipei, Taiwan: Department of Budget, Accounting and Statistics, Taipei City Government. 